\title{
[ARTICLE]
}

\section{SEMI-LEXICAL CATEGORIES IN WORD-FORMATION: A CASE STUDY IN JAPANESE MIMETIC COMPOUNDS}

\author{
RYOHEI NAYA and KEITA IKARASHI \\ University of Tsukuba / JSPS Research Fellow and \\ University of Aizu, Junior College Division
}

\begin{abstract}
Although various studies have investigated semi-lexical categories, these categories seem to remain poorly understood (Corver and van Riemsdijk (2001a)). This is partly because data in the literature is mostly limited to the phrasal level and to European languages. To deepen our understanding of semi-lexical categories, this paper addresses Japanese compounds which include mimetics as their right-hand constituent (e.g. kabe-don 'wallMim'). These mimetic compounds show peculiar characteristics in light of the right-hand head rule. To account for these peculiarities, we propose that a silent semi-lexical verbal noun occupies the head position of the mimetic compounds. Thus, our proposal will shed new light on semi-lexical categories.*
\end{abstract}

Keywords: semi-lexical categories, mimetics, compounding, right-hand head rule, verbal nouns

\section{Introduction}

The distinction between lexical and functional categories is fundamental in the field of linguistics. Generally, lexical items can be classified in either of these categories based on certain contrastive properties. A number of such properties have been identified so far, as summarized by Corver

* This paper is a revised and extended version of a poster presentation at the 8th Meeting of Formal Approaches to Japanese Linguistics held at Mie University on February 18-20, 2016. We express our sincere gratitude to Yukio Hirose, Nobuhiro Kaga, Masaharu Shimada, Naoaki Wada, Masaru Kanetani, Akihiko Sakamoto, Tatsuhiro Okubo, Hiroko Wakamatsu and two anonymous reviewers for their invaluable comments and suggestions. We have also benefited from the discussion with participants in the meeting of the Lexicon Study Circle held in March 2016. This work was supported in part by the Japan Society for the Promotion of Science (Grant-in-Aid for JSPS Research Fellow, Grant No. 16J01676).

English Linguistics 33: 2 (2017) 377-414 -377-

(C) 2017 by the English Linguistic Society of Japan 
and van Riemsdijk (2001a), with one striking example relating to semantic content. Lexical categories contain lexical items with a concrete semantic content. On the other hand, functional categories are composed of lexical items with abstract meanings as they primarily perform grammatical functions by, for example, marking "tense, modality, definiteness, number, degree, interrogativity" (Corver and van Riemsdijk (2001a: 1)). Functional items "glue the content words [i.e. lexical categories] together, to indicate what goes with what and how" (Corver and van Riemsdijk (2001a: 1)). Previous studies have clarified characteristics distinguishing between the two categories; this made the distinction more precise, thereby contributing to our understanding of natural language.

Research on questions relating to categories, however, has also discovered another type of category: it behaves like a lexical category in some respects and like a functional category in others. This in-between category is termed a "semi-lexical category" (Corver and van Riemsdijk (2001a)). Emonds $(1985,2000,2001)$, for example, argues that nouns, verbs, adjectives and prepositions, though generally classified as lexical, fall under the semi-lexical category when they have properties characteristic of functional categories. ${ }^{1}$ One such property is the lack of specific semantic content. Emonds $(2000,2001)$ attributes this property to feature compositions in lexical entries. He assumes that lexical entries are composed of "cognitive syntactic features," such as $[ \pm \mathrm{N}],[ \pm \mathrm{V}]$ and $[ \pm \mathrm{LOCATION}]$, and "purely semantic features." The former features "play a central role in both syntax and at Logical Form" but the latter ones "are not used in syntax" (Emonds (2000: 12)). Based on this distinction, Emonds defines semi-lexical items as verbs, nouns, adjectives and prepositions whose lexical entries consist only of cognitive syntactic features, and thus as items that contribute only to grammatical function. As examples of "semi-lexical adjectives," Emonds (2001: 36) refers to the adjectives real, pretty, awful and damned in (1b).

(1) a. The book seemed \{real / pretty / awful / damned\}.

b. She seemed $\{$ real / pretty / awful / damned $\}$ upset / happy\}. In (1a), these adjectives are used as ordinary, that is, lexical adjectives. In (1b), on the other hand, they serve as functional categories as they lack their original lexical meanings and simply express an extreme degree by modifying the adjectives upset and happy. Hence, they are to be regarded

1 In Emonds (1985, 2000), the term "grammatical" is used instead of "semi-lexical." Though the terms differ, the two label the same category. 
as semi-lexical items.

Corver (2008) provides another characterization of semi-lexical elements. Following Emonds' (2000, 2001) definition of semi-lexical categories, Corver argues that certain semi-lexical items can be silent in the sense of Kayne $(2005,2007)$. Kayne $(2005: 241,242)$ posits the existence of silent nouns in contexts such as (2a).

(2) a. a few books b. a few NUMBER books

In (2a), given that few is an adjective, the co-occurrence of an indefinite article with the plural noun books is problematic. This undesirable situation can be resolved if we assume the silent noun $N U M B E R$, which is analyzed as mediating between $a$ few and books.

Various studies have tried to shed light on the properties of semi-lexical categories, but these categories remain poorly understood, particularly when compared with regular lexical and functional categories. Semi-lexicality, in this sense, is at the frontier of research in the system of syntactic categories, thus requiring further research. In fact, Corver and van Riemsdijk (2001a: 10) list various questions that should be addressed in the study of semilexical categories. Some of these include: (i) what lexical items can be classified into semi-lexical categories; (ii) what properties differentiate them from ordinary lexical and functional categories; and (iii) what licenses these categories? The papers collected in Corver and van Riemsdijk (2001b) independently study semi-lexical categories and answer questions like these from various viewpoints. Unfortunately, there are poorly explored areas in the frontier we are attempting to examine. Among the unexplored areas of semi-lexical categories is that of word-formation in which semi-lexical items are involved. Numerous studies have focused on semi-lexical elements in the context of phrase formation, but very little attention (to the authors' knowledge) has been paid to those in word-formation (except for a few studies such as Shimada (2013)). We propose that it is not enough to focus on the phrasal level when studying semi-lexical categories because there should be semi-lexical items that can only be identified by exploring the field of word-formation, as will be indicated in this paper. Another unexplored field is related to the language types that have been investigated in the literature. Previous studies are mostly concerned with European languages. Non-European languages including Japanese are thus new fields in the study of semi-lexical categories. Given the variability of lexical categories in languages, it is desirable to advance the study to encompass a wide range of languages in order to broaden our knowledge of semi-lexical categories in natural language. For instance, Japanese has two lexical cate- 
gories that are not found in European languages: verbal nouns and adjectival nouns (Shibatani (1990)). These categories, as we will demonstrate below, should not be overlooked in the study of semi-lexical categories.

Hoping to contribute to a better understanding of semi-lexical categories, we will clarify some aspects of semi-lexical categories by investigating a certain kind of Japanese compound. More precisely, we will examine Japanese compounds containing mimetics as right-hand constituents, which to our knowledge have not been addressed in previous studies. We will investigate such compounds with respect to semi-lexical items, providing a new insight into semi-lexical categories.

This paper is organized as follows. Section 2 introduces Japanese mimetic compounds, and clarifies the issue that we will address in this paper. To resolve this issue, Section 3 proposes that mimetic compounds are headed by the semi-lexical verbal noun $A C T I O N$. Section 4 provides supporting evidence for the proposal in Section 3. Section 4.1 introduces an alternative analysis depending on the reanalysis process, which makes it unnecessary to assume the semi-lexical verbal noun $A C T I O N$ in mimetic compounds. However, this analysis will be shown to be inferior to ours when a certain semantic restriction on the left-hand element of mimetic compounds is considered. Section 4.2 discusses another possibility where mimetics themselves receive a verbal noun status without recourse to the semi-lexical element $A C T I O N$. This possibility will be rejected from both empirical and theoretical perspectives. After excluding the two alternatives to our proposal, we will provide in Section 4.3 another piece of supporting evidence from the perspective of recoverability, which requires silent nouns to occur in an environment where their presence and semantic content can be recovered (Kayne (2005)). Section 5 addresses a question concerning the structural status of mimetic compounds. Specifically, we will first examine the possibility that mimetic compounds are a type of postsyntactic compound, as discussed in Shibatani and Kageyama (1988). We will then turn down this possibility by showing several discrepancies between these two types of compounds, concluding that mimetic compounds are formed lexically. Section 6 discusses the theoretical implications for semi-lexical categories. Section 7 concludes this paper.

2. Mimetic Compounds and Their Basic Properties

2.1. Compounds with Mimetics as Their Right-Hand Constituents Japanese is rich in mimetics, sound-symbolic words that "represent 
sounds, shapes, texture, or something more abstract such as feelings" (Tsujimura (2005: 137)), as exemplified in (3).

(3) don 'thud,' wan-wan 'bowwow,' syut(-to) 'swish,' kira-kira 'glittering,' sowa-sowa 'restless,' beta-beta 'sticky'

Typically, the mimetics don 'thud,' wan-wan 'bowwow' and syut(-to) 'swish' describe the sounds produced by certain actions and kira-kira 'glittering,' sowa-sowa 'restless' and beta-beta 'sticky' express visual qualities, manners of actions and textures of something or someone. According to Kita (1997), mimetics are semantically distinguished from other words. Kita decomposes their meaning into two dimensions: the analytic dimension and the affecto-imagistic dimension. The former is the dimension where "[a] thought or experience is represented as a proposition [which can be] decomposed into semantic partials," such as quantifiers, bound variables, logical operators and semantic categories like agent, patient and action, and "[a] certain set of combinatoric recursive rules [like function-argument schema (e.g. action (agent, patient))] organizes these semantic partials into a hierarchical structure" (Kita (1997: 386)). This dimension is "decontextualized in the sense that it is removed from subjective experience" (Kita (1997: 387)). The affecto-imagistic dimension, on the other hand, is where "language has direct contact with sensory, motor, and affective information" (Kita (1997: 380)). Unlike the analytic dimension, the affecto-imagistic dimension "[does] not include the rational construal of [an experience] based on such things as agentivity and causality" (Kita (1997: 387)). Kita argues that mimetics' meaning belongs to the affecto-imagistic dimension, and thus that they awaken native speakers' intuition "that the sound-meaning relationship is direct, immediate, and nonarbitrary" (Kita (1997: 381)).

Along with native Japanese and Sino-Japanese words, mimetics compose an independent lexical stratum of the Japanese vocabulary because of their particular properties (cf. Shibatani (1990)). It is noteworthy that they "inherently do not have categorial status" (Tsujimura (2005: 144)); this status is specified according to the syntactic environments in which they appear. For example: ${ }^{2}$

2 The following abbreviations are used in the glosses of examples in this article: Acc = accusative, $\mathrm{Adv}=$ adverb, $\mathrm{Cop}=$ copula, Dat $=$ dative, $\mathrm{Gen}=$ genitive, Infl $=$ inflection, Mim $=$ mimetic, Nom $=$ nominative, Part $=$ particle, Past $=$ past tense, Quot $=$ quotative, Stat $=$ state, Top $=$ topic. 
(4) a. Kodomo no seiseki ga waruku iraira ga child Gen grade Nom bad irritation Nom tamatta. [Noun] accumulate.Past

'Since my child's grades have been bad, my irritation has accumulated.'

b. Ano hito wa itumo iraira-to hanasu. [Adverb] that person Top always irritated speak 'That person always speaks in an irritated manner.'

c. Otto no kudaranai hanasi ni iraira-sita. [Verb] husband Gen silly talk at irritated-get.Past 'I got irritated by my husband's silly talk.'

(Tsujimura (2005: 144), with modifications) In (4a), iraira occurs with the nominative marker -ga. Since -ga normally accompanies nouns, the category of iraira in (4a) is specified as a noun. In (4b), iraira is followed by the quotative particle -to, by which iraira can modify the verb hanasu 'speak'; thus it gains the status of an adverb. Finally, iraira in (4c), which is accompanied by the light verb suru 'do,' functions as a verb. Among these three categories, the adverbial usage of mimetics is considered to be the most typical (cf. Hamano (1998), Akita (2009)).

Mimetics, as briefly mentioned above, show some idiosyncratic characteristics, which have attracted considerable attention. This does not mean, however, that we have a full understanding of their nature; there seem to be untouched phenomena concerning mimetics. Among these unexplored phenomena is a case where mimetics occur as right-hand constituents of expressions consisting of two words. Below are some attested examples: ${ }^{3}$

3 The examples in this paper cited from the Internet were collected from November 2015 to March 2016 (except for example (5e), which was found in June 2016). When describing the meaning of kabe-don in English, we referred to the following Internet article: Kabe-don! Cornering Women Against the Wall Goes Viral, available at http:// www.japancrush.com/2012/pictures/kabe-don-cornering-women-against-the-wall-goes-viral. $\mathrm{htm}$. We also consulted the Internet dictionary weblio (http://ejje.weblio.jp/) in the description of mune-kyun. 
(5)
a. kabe-don
wall-Mim
'the act of a man cornering a woman by placing his arm(s) against a wall with a thud'
b. ago-kui
c. mune-kyun heart-Mim
d. kao-piku face-Mim chin-Mim 'the act of a man tipping a woman's chin up with his fingers' 'one's heart skipping a beat'
'twitching of one's face' (http://coco.to/movie/20955/review $\operatorname{good} / 29$ )
e. zitensya-burabura bicycle-Mim
f. neko-banban cat-Mim
'the act of hanging around by bicycle' (http://arufa.hatenablog.jp/entry/2008 1004)
'the act of banging the hood of a car before starting the engine in order not to injure a cat hiding under the hood in a cold season'
(http://headlines.yahoo.co.jp/hl?a=2015 1119-00000097-it_nlab-life)

As we will discuss in detail in Section 3, these expressions refer to specific events. Kabe-don in (5a), for instance, describes a specific act committed by a man directed toward a woman, and mune-kyun in (5c) is an emotional experience as in, for example, a romantic situation. The meaning of these expressions depends partially on the (non-)reduplication of mimetics. In (5a)-(5d), the mimetics are not reduplicated, which iconically means that the events occur just once. In (5e) and (5f), on the other hand, the mimetics bura and ban are reduplicated; zitensya-burabura and neko-banban thus refer to repeated or continuous actions.

Let us here focus on the phonological aspect of these expressions. They show characteristics of compounds; in most cases, the compounds' constituents lose inherent accents, and the compounds have one accent (Kubozono (1995)). For instance, yubi-pattin 'finger-Mim (= finger-snap)' follows this pattern (the location of accent is marked by “' " "):

(6) yubí + pattín $\rightarrow$ yubipáttin

Although the noun $y u b i$ and the mimetic word pattin have their own accents (the left side of the arrow), the resulting compound receives one accent, constituting a unified phonological word (the right side of the arrow). Notice that some expressions in (5) do not have accents. Kabe-don in (5a) is one such expression: 
(7) kabe + dón $\rightarrow$ kabedon

The mimetic don is an accented word as indicated on the left side of the arrow in (7), but it is deaccented in kabe-don. This phonological pattern is also observed in a certain type of compounds. For example, syákai 'society' and tóo 'party' are accented words, but when they are combined, the resulting compound lacks an accent, i.e. syakaitoo 'Socialist Party' (Kubozono (1988: 153)). This example shows that deaccenting is one way to form a unified phonological word. Although kabe-don differs from this example in that the latter is a noun-noun compound, we can conclude that kabe-don shows a compound accent pattern. ${ }^{4}$

Having seen expressions like those in (5) with accentual characteristics of compounds, we now turn to their morphological characteristics. These expressions exclude any syntactic operation that violates Lexical Integrity. For example, adjectives are not allowed to modify the left-hand element of a compound. Thus, the adjective togatta 'sharp' in (8a) cannot function as a modifier of ago 'chin,' the left-hand element of ago-kui. The use of pronouns is also not permissible. For example, soko-don in (8b) is completely ungrammatical.

$$
\begin{aligned}
& \text { a. *togatta [ago-kui] } \\
& \text { sharp [chin-Mim] } \\
& \text { intended reading: tipping a sharp chin } \\
& \begin{array}{l}
\text { b. *nnanoko-ga kabe-ni yorikakate-ita. Otokonoko-wa } \\
\text { girl-Nom } \quad \text { wall-against lean-Stat.Past boy-Top } \\
\text { onnanoko-ni tikayori, soko-don sita. } \\
\text { girl-Dat approach there-Mim do.Past }
\end{array}
\end{aligned}
$$

'A girl was leaning against the wall. A boy approached her and cornered her by placing his arms against it with a thud.'

Semantically, expressions like (5), though perhaps not all, show non-compositionality, a typical characteristic of compounds. Kabe-don, for instance, does not literally mean someone's act of banging on a wall; it has a more specific meaning like 'the act of a man cornering a woman by placing his $\operatorname{arm}(\mathrm{s})$ against a wall with a thud.'

These facts lead us to conclude that examples like those in (5) are compounds. For convenience, let us call compounds containing mimetics as their right-hand elements as "mimetic compounds." We can encounter

${ }^{4}$ Not all noun-noun compounds are deaccented. See Kubozono (1988, 1995) and Tsujimura (2014) for other accent patterns in these compounds. 
various types of mimetic compounds in our daily lives, which indicates that mimetic compounds are productive.

\subsection{An Apparent Peculiarity of Mimetic Compounds}

Mimetic compounds pose an interesting question when considering the right-hand head rule (RHR), which defines the head in the morphological domain: "In morphology, we define the head of a morphologically complex word to be the righthand member of that word" (Williams (1981: 248)). Given this rule, the heads of mimetic compounds ought to be mimetics. Mimetics should thus be categorial determinants of mimetic compounds as a whole, which means that the compounds should have the same categorial properties as mimetics. However, this is not the case; rather, their category is limited to that of verbal noun (henceforth VN).

To illustrate this point, let us first consider the primary function of mimetics. As mentioned above, mimetics are typically used as adverbs (see example (4b)). It is predicted that mimetic compounds should also serve as adverbs if their heads are mimetics. Contrary to this prediction, however, the examples in (9) show that mimetic compounds cannot co-occur with the marker - to, and lack the ability to modify verbs.
a. *Taro-wa Hanako-o kabe-don-to osita.
Taro-Top Hanako-Acc wall-Mim-Quot push.Past
lit. 'Taro pushed Hanako against the wall with a thud.'
b. *Taro-wa kuruma-o neko-banban-to tataita.
Taro-Top car-Acc cat-Mim-Quot tap.Past

lit. 'Taro banged his car in order not to injure a cat that might be hiding under the hood.'

Kabe-don in (9a) and neko-banban in (9b) are followed by -to, functioning as modifiers of the verb. Unlike modification by mimetic words, such modification by mimetic compounds results in ungrammatical sentences. ${ }^{5}$ Hence, mimetic compounds lack the adverbial usage typical of mimet-

5 An anonymous reviewer has pointed out that, as opposed to our judgment, the examples in (9) sound natural to him/her, which raises a fundamental question over our generalization that mimetic compounds are restricted to VN. To solve this issue, we tentatively assume that the derivation involved in cases where the examples in (9) are acceptable differs from those where they are unacceptable: When acceptable, they are derived as postsyntactic compounds (see Section 5, where we will demonstrate that mimetic compounds are not related to postsyntactic compounds). For instance, (9a) is formed from the underlying structure in (ia) by shortening the accusative marker $-o$ as in (ib), 
ics in general.

While adverbial usage is not observed, we can easily find mimetic compounds used in nominal environments. For example:

$$
\begin{aligned}
& \text { a. mizukara-no danna-ni 'kabe-don'-o yookyuu } \\
& \text { own-Gen husband-Dat wall-Mim-Acc requirement } \\
& \text { sita }[\ldots] \\
& \text { do.Past }
\end{aligned}
$$

'[She] required her own husband to do kabe-don.'

(http://virates.com/funny/07165456)

b. 'kabe-don'-ga ryuukoo sita haikei $[\ldots]$

wall-Mim-Nom vogue do.Past background

'factors behind the increasing popularity of kabe-don'

(https://ja.wikipedia.org/wiki/\%E5\%A3\%81\%E3\%83\%89\%

E3\%83\%B3)

Kabe-don in (10a) and (10b) is followed by the accusative case marker - $o$ and the nominative case marker $-g a$, respectively, which suggests that mimetic compounds have a nominal status.

In addition, mimetic compounds can, at first glance, also be used verbally, as indicated by the following examples:
a. kabe-don (suru)
wall-Mim (do)
b. ago-kui (suru)
chin-Mim (do)
c. mune-kyun (suru)
heart-Mim (do)
d. kao-piku (suru)
face-Mim (do)
e. zitensya-burabura (suru)
bicycle-Mim (do)
f. neko-banban (suru)
cat-Mim (do)

As noted in Section 2.1, mimetics serve as verbs when followed by the light verb suru. Thus, the examples in (11), where mimetic compounds can

where ":" indicates that kabe and don constitute a postsyntactic compound; we note in passing that (ia) sounds unnatural because of the double object marking.

(i) a. Taroo-wa Hanako-o kabe-o don-to osita.

Taro-Top Hanako-Acc wall-Acc Mim-Quot push.Past

'Taro pushed Hanako against the wall with a thud.'

b. Taroo-wa Hanako-o [kabe:don]-to osita.

One piece of evidence to support this tentative analysis comes from the interpretation of the compounds. As noted in the text, kabe-don has a non-compositional interpretation. (ib), on the other hand, seems to be compositionally interpreted if acceptable at all: kabe:don merely describes the sound caused by banging the wall. There may be other speakers who accept sentences like those in (9), but in this paper, we assume that they are unacceptable on the basis of our judgment. We leave this issue open for future research. 
co-occur with suru, seem to indicate their ability to serve as verbs. However, a moment's reflection will make it clear that mimetic compounds are combined with suru in a different way from mimetics. As shown in (12a), mimetic verbs allow the quotative marker -to to appear between mimetics and suru, but not the accusative case marker -o. On the other hand, mimetic compounds exhibit the opposite grammatical pattern: as exemplified in (12b), they tolerate the intervention of $-o$, but not $-t o$, between the mimetic and suru.
a. dondon $\left\{\right.$-to $\left./ *_{-o}\right\}$ suru
Mim $\{-$ Quot / -Acc $\}$ do
'(Someone) thumps (something).'
b. kabe-don $\{-o / *$-to $\}$ suru

This leads us to conclude that mimetic compounds do not have verbal usage, and are exclusively used as nominal expressions. Notice here that nominal expressions that can co-occur with suru are considered to be VNs. For instance, the VN benkyoo 'study' permits the form benkyoo-suru 'to study,' whereas the noun enpitu 'pencil' excludes co-occurrence with suru (i.e. *enpitu-suru 'do pencil') (cf. Kageyama (1993: 256)). Furthermore, when used with suru, VNs can be followed by the accusative marker -o (e.g. benkyoo-o suru). Thus, the examples given above suggest that mimetic compounds are VNs (not just nouns). In fact, their interpretation is related to eventuality. Kabe-don in (5a), for example, is not a mimetic describing the sound don 'thud,' but instead expresses the action of banging a wall strongly. Thus, kabe-don is a kind of action. Likewise, mune-kyun in $(5 \mathrm{c})$ does not describe the manner of kyun, but the emotional experience of feeling one's heart skipping a beat; it is a type of experience. Kao-piku in (5d) is also not a mimetic representing the manner of piku 'twitchily, twitching,' but describes the movement of one's face in a particular way. ${ }^{6}$

The above observation raises an interesting question: Why is the category of mimetic compounds confined to VNs? As noted above, they appear to be headed by mimetics, because of which the RHR predicts that the compounds should also be used as adverbs or verbs. ${ }^{7}$ To answer this question,

\footnotetext{
${ }^{6}$ Another piece of evidence showing that mimetic compounds are VNs is given in footnote 15 in Section 4.2.

7 After submitting the second draft of this paper to EL Editor, we found that Kageyama and Saito (2016: 16) also mention what we call mimetic compounds. They point out that "mimetics resist becoming heads" because they are typically adverbs which rarely function as heads of compounds. They touch on the possibility of analyzing mi-
} 
we will introduce the semi-lexical category into the analysis of mimetic compounds.

\section{Proposal}

Before addressing the question we have raised, let us first consider the interpretation of mimetic compounds. The mimetic compounds in (5) can be literally paraphrased in sentential form with the light verb suru 'do,' as shown in (13). ${ }^{8} \quad$ (Notice that the following sentences are provided to clarify the semantic relation between the compounds' constituents; we are not saying that they are underlying forms from which mimetic compounds are derived. The derivational relation between mimetic compounds and sentences like those in (13) will be rejected in Section 5.)
a. Kabe-o don-to suru. wall-Acc Mim-Quot do 'Someone bangs the wall.'
b. Ago-o kuit-to suru. chin-Acc Mim-Quot do 'Someone tips someone's chin up.'
c. Mune-ga kyun-to suru. heart-Nom Mim-Quot do 'One's heart skips a beat.'
d. Kao-ga pikut-to suru. face-Nom Mim-Quot do 'One's face twitches.'
e. Zitensya-de [mati-o] burabura(-to) suru. bicycle-by town-Acc Mim-Quot do 'Someone hangs around in the town by bicycle.'

metic compounds, but do not provide further discussion of the peculiar behavior under consideration.

${ }^{8}$ When used with the light verb suru, mimetics differ from each other in whether the quotative marker -to is obligatory. In (13a)-(13d), -to is normally required, whereas in (13e) and (13f), it is optional. This observation can be attributed to a phonological tendency among mimetics to prefer being four morae long (Nasu (2002)). More specifically, mimetics consisting of three moras $((13 \mathrm{a})-(13 \mathrm{~d}))$ incorporate -to into their prosodic structure, becoming a four morae long prosodic word; that is why -to obligatorily appears. Mimetics consisting of four moras ((13e) and (13f)), on the other hand, does not need to depend on -to to follow the phonological tendency, so the use of -to is optional. See Nasu (2002) for further discussion. 
f. Neko-no tameni [kuruma-no bonnetto-o] banban(-to) suru. cat-Gen for car-Gen hood-Acc Mim-Quot do 'Someone bangs [the hood of a car] for cats.'

What is important here is that suru cannot take a subject or object by itself, as shown in (14).

(14) a. *Kabe-o suru.

b. *Ago-o suru

c. *Mune-ga suru.

d. *Kao-ga suru.

e. *Zitensya-de [mati-o] suru.

f. *Neko-no tameni [kuruma-no bonnetto-o] suru.

The examples in (13) and (14) show that the light verb suru and a mimetic together form one verb, which makes it possible for that verb to take arguments (cf. Kageyama (2007)). Moreover, the argument structure of mimetic verbs is determined by the mimetic type suru is combined with. The examples don-to suru in (13a) and kuit-to suru in (13b) respectively occur with the accusative nouns kabe-o and ago-o, which indicates that they behave as transitive verbs. Examples (13c) and (13d), in which only nominative nouns (mune-ga and kao-ga) appear, show that kyun-to suru and pikutto suru function as intransitive verbs. In (13e), burabura(-to) suru refers to one's intentional act of hanging around, and can be classified into the class of verbs like aruku 'walk' (which Kageyama (2007) regards as a verb of manner of motion). So it is assumed to have an intransitive, more specifically, unergative, property (as the bracketed part suggests, burabura(-to) suru, like a number of unergative verbs, can take a traversal path phrase (cf. Kageyama (2007); see also Shibatani (1978) for a discussion of the syntactic and semantic relation between unergative verbs and accusative marked phrases)). In (13f), neko is not in an argument relation with the verb banban(-to)-suru, but is interpreted as an adjunct. ${ }^{9}$ However, as the bracketed portion suggests, banban(-to)-suru functions as a transitive verb.

With this in mind, let us return to mimetic compounds. As mentioned, these can be paraphrased as sentential forms. This paraphrase clarifies that the left-hand constituents in these compounds establish argument-predicate relations in (13a)-(13d) or adjunct-predicate relations in (13e) and (13f) with the mimetics. Recall that mimetics belong to the affecto-imagistic

\footnotetext{
${ }^{9}$ Neko can also be interpreted to be an object if the compound is used in other contexts. In this case, the compound means 'Someone bangs a cat.'
} 
dimension (Kita (1997)). This implies that mimetics by themselves cannot semantically enter into an argument-predicate or an adjunct-predicate relation with the left-hand constituents, which belong to a different semantic dimension from mimetics, namely the analytic dimension. Additionally, they are assumed to be morpho-syntactically unable to make such relations because of their lack of categorial status. Thus, they require some "glue" to be connected with other words. It is reasonable to say that, in the case of sentential forms, mimetics, as shown in (13), depend on the light verb suru to gain a verbal status that makes it possible to establish the relations under discussion (see also Tamori and Schourup (1999: 55)). At the morphological level, we can thus predict that the mimetics in mimetic compounds also have recourse to certain elements that enable mimetics to establish argument-predicate or adjunct-predicate relations with the left-hand elements. We thus propose that these relations are ensured by the existence of a silent VN that functionally plays a similar role to the light verb suru 'do' in (13); the $\mathrm{VN}$, located in the right-most position, combines with a mimetic, and enables the resulting structure (i.e. [Mim VN] $]_{\mathrm{VN}}$ ) to semantically and morpho-syntactically take arguments or adjuncts. Note that the VN we posit for mimetic compounds lacks semantic content since it behaves like the light verb suru, and only serves to ensure a relation between the mimetic and the left-hand element; it therefore only has syntactic features. Thus, we can say that it is a silent semi-lexical item. Let us represent the silent $\mathrm{VN}$ in mimetic compounds by the notation ACTION. It is this silent VN that heads mimetic compounds. Under our proposal, mimetic compounds, such as the examples in (5), have the structures indicated in (15), where $x$ and $y$ represent an external argument and an internal argument, respectively. ${ }^{10}$

10 One might think that the semi-lexical VN $A C T I O N$ has an effect on the accent pattern of mimetic compounds. However, we assume that $A C T I O N$ is not involved in the phonological computation, since it is silent and therefore invisible to the phonological component. Thus, as discussed in Section 2.1, the accent pattern is exclusively determined based on the overt elements, namely the left-hand element and a mimetic. 
(15) a.

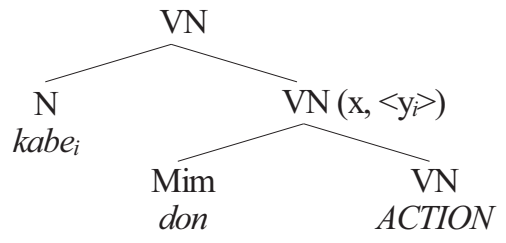

b.

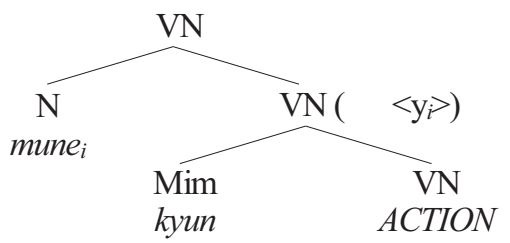

c.

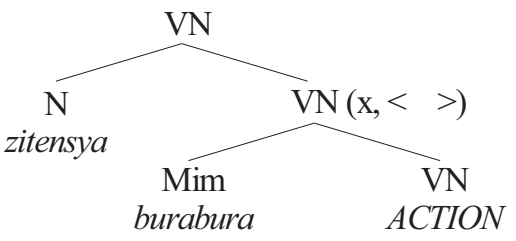

d.

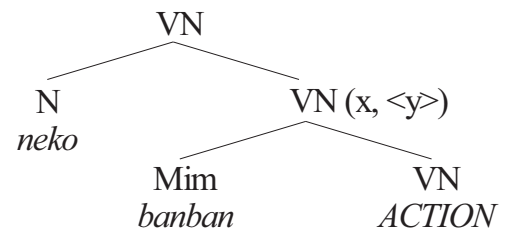

In mimetic compounds, the head $A C T I O N$ is associated with eventuality, but has no concrete content because it is a semi-lexical category. A mimetic, the non-head, modifies $A C T I O N$, specifying the type of event, as is observed in, say, maguro-turi 'tuna-fishing (= to fish tuna),' where the nonhead maguro specifies the type of fishing. In other words, compounding a mimetic with the semi-lexical $A C T I O N$ yields a VN that has a specific argument structure. In (15a), for example, the mimetic don describes the sound caused by someone/something's colliding with someone/something. Thus, the combination of don and $A C T I O N$ is assumed to form a $\mathrm{VN}$ that is similar to transitive verbs in that it can introduce two arguments, one of which collides with the other. The VN compound don-ACTION is then compounded with the noun kabe, which bears an object-oriented relation to don-ACTION. This forms the mimetic compound kabe-don. Ago-kui in (5b) is assumed to have the same structure as kabe-don (see the paraphrase in (13b)). On the other hand, the combination of kyun and ACTION in (15b) is similar to intransitive verbs in that it only introduces one argument. The VN compound kyun-ACTION is, in turn, combined with the 
noun mune, which bears a subject-oriented relation to kyun-ACTION; the mimetic compound mune-kyun is thus formed. Notice here that kyun$A C T I O N$ is assumed to be equal to an unaccusative. Firstly, mune-kyun means an unintentional change occurring in one's heart, namely 'one's heart skipping a beat.' For another, the light verb suru in the paraphrase in (13c) can be replaced with the verb naru (i.e., mune-ga kyun-to naru.). Naru represents change of state, that is, unaccusativity (Kageyama (1993); see also Kageyama (1996)). Thus, the fact that kyun is compatible with naru indicates its potential relation to unaccusativity. We assume that the unaccusative nature of kyun is inherited to kyun-ACTION, which thus has the same argument structure as unaccusative verbs. Piku in kao-piku in (5d) can also be considered a similar example (cf. kao-ga pikut-to naru.). Thus, we assume that kao-piku in (5d) has the same structure as mune-kyun. In $(15 \mathrm{c})$, the combination burabura-ACTION refers to the intentional act of hanging around. In this sense, as the sentential paraphrase in (13e) shows, it is assumed to have an unergative characteristic. Notice that, unlike kabe in (15a) and mune in (15b), the noun zitensya is not considered an argument of burabura-ACTION; it evokes the adjunct-oriented relation 'by bicycle.' It is assumed that compounds where heads are unergative VNs generally take an adjunct, not an external argument, as their left-hand element (cf. Kageyama (1993)). (15c) thus conforms to this general tendency. In the case of neko-banban in (15d), the mimetic banban and ACTION together form a VN compound that is similar to a transitive verb. The noun neko, however, does not establish an argument relation with the VN banban-ACTION; rather, it bears the adjunct-oriented relation 'for the sake of a cat. ${ }^{11,12}$

11 An anonymous reviewer has raised the possibility that neko in neko-banban establishes the indirect object-oriented relation with banban-ACTION because neko is assumed to be a beneficiary of the act of banging the car hood, as with Mary in John bought Mary a book. However, indirect objects are normally not allowed to be compounded with verbal elements (see Kageyama (1993: 198) for further discussion). We will thus assume in our discussion that neko induces the adjunct-oriented relation.

12 An anonymous reviewer has pointed out that don-ACTION of kabe-don can introduce its subject, i.e. an external argument, with the genitive marker -no in its Spec position, as in (i).

(i) John-no kabe-don kakkoii.

John-Gen wall-Mim cool

'John's kabe-don is cool.'

In this example, John can be interpreted as the subject of don-ACTION. We assume that the argument structure of don-ACTION is inherited by the mimetic compound kabe-don 
We are now in a position to answer the question raised in Section 2.2: Why is the category of mimetic compounds confined to VN? Mimetic compounds include the silent semi-lexical VN $A C T I O N$ in their head position; their categorial status is determined by $A C T I O N$. This is why mimetic compounds are VNs. Semi-lexical categories provide us with a solution for capturing the peculiar characteristics of mimetic compounds. This means that they play a crucial role at the word-formation level, to which previous studies have paid little attention. In what follows, we will present evidence that supports our proposal.

\section{Supporting Evidence: The Categorial Status of Mimetic Compounds}

This section demonstrates the necessity, as proposed in Section 3, to assume the semi-lexical VN $A C T I O N$ in mimetic compounds. In Sections

as a whole. The inheritance of arguments can be easily found in compounds headed by VNs. For example, Sugioka (1989: 171) gives the following example:

(ii) mondai-no sooki-kaiketu problem-Gen early-resolution

"an early resolution of the problem"

The compound sooki-kaiketu contains the VN kaiketu as a head. Importantly, the noun mondai corresponds to the object of kaiketu. This can be explained by assuming that the argument structure of the head kaiketu is inherited by the whole compound. The parallelism between this example and the example in (i) supports the assumption that don-ACTION contains the argument structure, which is inherited by the whole mimetic compound. We would like to thank the reviewer for his or her invaluable comments.

The same reviewer has also pointed out that mune-kyun can co-occur with Hanako-no, as in (iii); this fact shows the transitive nature of kyun-ACTION.

(iii) Hanako-no mune-kyun

Hanako-Gen heart-Mim

'Hanako's heart's skipping a beat'

However, as discussed in context, kyun-ACTION can be considered as unaccusative; Hanako cannot be interpreted as the external argument kyun-ACTION. In fact, (iii) cannot be paraphrased into (iv), where Hanako occurs with the nominative marker and mune with the accusative marker.

(iv) *Hanako-ga mune-o kyun-to suru.

Hanako-Nom heart-Acc Mim-Quot do

lit. 'Hanako experiences her heart skipping a beat.'

Rather, we suggest the following paraphrase, in which Hanako-ga and mune-ga appear as multiple subjects.

(v) Hanako-ga mune-ga kyun-to suru.

Hanako-Nom heart-Nom Mim-Quot do

'Hanako experiences her heart skipping a beat.'

So, as noted in the text, we assume that kyun-ACTION carries unaccusativity. 
4.1 and 4.2, we will discuss alternative analyses that, unlike ours, do not postulate $A C T I O N$ in the structure of mimetic compounds. These alternatives will then be rejected because of empirical and/or theoretical problems, which our analysis can successfully account for. In Section 4.3, we will argue for the existence of $A C T I O N$ in mimetic compounds based on how the compounds do not turn from $\mathrm{VN}$ into $\mathrm{N}$ similar to certain deverbal compounds like kane-moti 'money-have (= a rich person).'

\subsection{Mimetic Compounds and Argument Structures}

In Section 3, we proposed that a mimetic compound is formed by first combining a mimetic with the semi-lexical VN ACTION and then combining the resulting structure with a noun. It should be noted here that there is another possible analysis: A mimetic and a noun are directly combined and the combined structure becomes a VN through certain processes such as reanalysis. This possibility is represented in (16).

(16) $\left[[k a b e]_{\mathrm{N}}[d o n]_{\mathrm{Mim}}\right]_{\mathrm{Mim}}$-reanalysis $\rightarrow[\text { kabe-don }]_{\mathrm{VN}}$ Under this alternative analysis, we do not need to assume the semi-lexical VN $A C T I O N$ to guarantee the categorial property of the compounds. However, there is a case that cannot be accounted for by the alternative analysis in (16). This case is, however, successfully captured by our proposal relying on the semi-lexical VN $A C T I O N$.

To illustrate this point, let us observe the interpretations of the left-hand elements in the mimetic compounds in (17).
a. kabe-don wall-Mim [Object]
b. atama-don head-Mim [Adjunct] (http://matome.naver.jp/odai/2141316277615429301)
c. *otoko-don man-Mim [Subject]

As noted in Section 3, kabe-don has a transitive interpretation in that it can be paraphrased as Kabe-o don-to suru (cf. (13a)). It was also pointed out that kabe in this example bears an object-oriented relation. In addition, there is another possible relation that the left-hand noun can have. Atamadon in (17b) means the act of a man cornering a woman by placing his head, instead of his $\operatorname{arm}(\mathrm{s})$, against a wall with a thud. That is, atama 'head' in this compound is an adverbial element expressing the means by which the act in question is undertaken. In this sense, atama has an interpretation similar to an adjunct. These examples indicate that the mimetic compounds allow their left-hand elements to be objects or adjuncts. However, the situation is different for otoko-don in (17c). This compound is formed to mean the act of otoko 'man' performing kabe-don. That is, the 
left-hand element otoko is interpreted as a subject. However, the compound cannot be interpreted in this way. This example suggests that a subject-oriented element cannot be the left-hand constituent of mimetic compounds.

Notice that subject-oriented elements are not entirely excluded from mimetic compounds. Recall that mune-kyun has an intransitive interpretation in that the compound can be paraphrased as Mune-ga kyun-to suru (cf. $(13 \mathrm{c})$ ). What is important here is that although mune is interpreted as a subject, the compound mune-kyun is fully acceptable.

(18) mune-kyun heart-Mim [Subject]

The examples in (17) and (18) show that there are some restrictions on the left-hand constituent of mimetic compounds. We will see below that the restrictions seem to be closely related to argument relations. It is difficult to account for why such restrictions are observed if we assume that mimetic compounds are formed by directly compounding a mimetic and the left-hand element as represented in (16). In (16), the left-hand element and a mimetic should be combined without restrictions as to argument relations, which makes it difficult to account for the ungrammaticality of the compound in $(17 \mathrm{c})$. On the other hand, we can explain the existence of such restrictions if, as we propose, a mimetic combines with the semi-lexical VN $A C T I O N$ and the resulting structure introduces arguments. As we will see, our proposal explains our observation in the same way as in the case of deverbal compounds, compounds headed by deverbal nominals.

Previous studies have clarified that the formation of deverbal compounds is constrained by the argument structure of the related verbs. To illustrate this point, let us first observe the following examples, which contain the transitive verb $k u$ ' 'eat.' 13

$$
\begin{array}{llll}
\text { a. ringo-kui } & \text { apple-eat 'eating of apples' } & \text { [Object] } \\
\text { b. te-gui } & \text { hand-eat 'eating with one's hand' } & \text { [Adjunct] } \\
\text { c. *kodomo-kui child-eat 'a child's eating' } & \text { [Subject] } \\
\text { cf. Kodomo-ga ringo-o te-de kuu. } & \\
& \text { child-Nom apple-Acc hand-with eat } & \\
& \text { 'The child eats apples with his/her hand.' }
\end{array}
$$$$
\text { ((19a, c): Kageyama (1993: 50), with modifications) }
$$

${ }^{13} \mathrm{Kui}$ in the compounds in (19a) is the adverbial form of the verb kuu 'eat.' In (19b), the form gui occurs because the initial consonant of kui has undergone sequential voicing, known as rendaku in Japanese. 
The compound in (19a), in which the left-hand position has ringo 'apple,' an object of the verb kuu 'eat,' is grammatical. In addition, te 'hand' in (19b), which can be interpreted as an adjunct, can also be the first constituent. However, the compound in (19c) is not permissible where kodomo 'child' is interpreted as the subject of the transitive verb. These data seem to show that elements corresponding to subjects are excluded from deverbal compounds. However, the situation is a little more complicated. Let us next observe the following example, which contains the intransitive verb kawaru 'change.' 14

(20) kokoro-gawari heart-change 'change of heart'

(Kageyama (1993: 50))

cf. Kokoro-ga kawaru. heart-Nom change

The compound kokoro-gawari can be paraphrased as kokoro-ga kawaru (heart-Nom change). As this paraphrase indicates, the first constituent of the compound kokoro is the subject of the verb kawaru. Unlike (19c), the compound is grammatical. The grammaticality of the compound in (20) shows that subject-oriented elements can appear in the deverbal elements in certain cases. What is crucial here is that the relations of the first constituents to the argument structures of the relevant verbs are different between (19c) and (20). When the subject of an intransitive verb is an external argument, the resulting compound is unacceptable; on the other hand, when it is an internal argument, the resulting compound is acceptable (cf. Kageyama (1993), Ito and Sugioka (2002)). Let us consider these analyses more concretely. The argument structure of the transitive verb $k u u$ 'eat' can be shown as in (21a), where $x$ and $y$ respectively represent an external argument and an internal argument. Typically, an external argument is realized as a subject. Thus, kodomo in (19c), which is interpreted as a subject, is the external argument of the verb $k u u$, yielding an unacceptable compound. Then, what about the intransitive verb kawaru? Note here that intransitive verbs can be classified as unergative or unaccusative verbs. Kawaru belongs to the latter type. It has been argued that unaccusative verbs like kawaru take internal arguments, as seen in (21b).
a. kuu 'eat' $(\mathrm{x},<\mathrm{y}>)$
b. kawaru 'change' $(<\mathrm{y}>)$

The internal arguments of unaccusative verbs are assumed to be realized as

14 As with the examples in (19), sequential voicing is observed in the compound in (20). The initial consonant of kawari, the adverbial form of kawaru, has undergone sequential voicing, yielding the form gawari in the compound. 
subjects. Thus, kokoro in (20) is actually an internal argument, and not an external argument. The compound in (20) is fully acceptable if we assume that only internal arguments can be subjects in deverbal compounds.

Let us return to mimetic compounds. As with deverbal compounds, mimetic compounds allow object-oriented elements and adjunct-oriented elements to occur in the left-hand position (e.g. in (17a) and (17b)). Besides this parallelism, the contrast between the compounds in (17c) and (18), where the left-hand elements are both interpreted as subjects, also shows a similarity to deverbal compounds. The argument structures of don-ACTION and kyun-ACTION in otoko-don and mune-kyun can be respectively represented as in (22a) and (22b).

(22) a. don-ACTION: (x, <y>) b. kyun-ACTION: $(<\mathrm{y}>)$

These argument structures mean that don-ACTION is transitive and that kyun-ACTION is unaccusative (see Section 3). Based on these argument structures, the (un)grammaticality of the compounds in (17c) and (18) can be explained as follows: As with the case of kodomo-kui in (19c), otoko-don is not grammatical because otoko in this compound is an external argument; in mune-kyun, on the other hand, mune is the internal argument of unaccusative kyun-ACTION, and thus the compound is grammatical, just as is kokoro-gawari in (20).

If we assumed that the left-hand element and a mimetic were directly combined as in (16), it would be difficult to explain the origin of the restriction on the first constituents of mimetic compounds: Based on such an assumption, nothing would ensure correct argument relations. On the other hand, it is a valid account for the grammaticality in (17) and (18) to assume that mimetic compounds contain structures where mimetics combine with the semi-lexical VN $A C T I O N$.

\subsection{Mimetics and Morphological Processes}

In this subsection, we will investigate another possible alternative to our proposal, namely the conversion of mimetics into verbal nouns. We will then argue that our analysis of mimetics as being combined with ACTION in forming mimetic compounds is superior to an alternative one that stipulates that mimetics undergo conversion.

According to Kageyama (1982), the major Japanese lexical categories are defined by the three basic lexical features $[ \pm \mathrm{V}],[ \pm \mathrm{N}]$ and $[ \pm \mathrm{A}]$, as in (23). 
(23)

$\begin{array}{lllll} & & \text { V } & \text { N } & \text { A } \\ \text { a. } & \text { verbs } & + & - & - \\ \text { b. nouns } & - & + & - \\ \text { c. } & \text { adjectives } & - & - & + \\ \text { d. } \text { adjectival nouns } & - & + & + \\ \text { e. } & \text { verbal nouns } & + & + & -\end{array}$

(Kageyama (1982: 218))

Kageyama $(1982,1993)$ assumes that converting from one category to another is a process of switching the feature specifications. In the case of V-to-N conversion, the $[-\mathrm{N}]$ feature of verbs is switched to $[+\mathrm{N}]$, as exemplified in (24) (see also Kageyama (1993: 182)).
a. turu $[+\mathrm{V},-\mathrm{N},-\mathrm{A}]$
to fish
b. turi $[+\mathrm{V},+\mathrm{N},-\mathrm{A}]$
fishing

In $(24)$, the $[-\mathrm{N}]$ feature of the verb turu 'to fish' is switched into $[+\mathrm{N}]$, producing the feature complex $[+\mathrm{V},+\mathrm{N},-\mathrm{A}]$. As a result, the $\mathrm{VN}$ turi 'fishing' is formed. The VN formed in this way can undergo further morphological processes such as compounding. For example, the VN turi can be combined with the noun sakana 'fish,' as in (25).

(25) $\left[[\text { sakana }]_{\mathrm{N}}-[\text { turi }]_{\mathrm{VN}}\right]_{\mathrm{VN}}$ (suru) fish-fish (do) 'angling, fishing' Since the VN is the right-hand constituent, the resulting compound sakanaturi has the category VN. Thus, it can be compatible with the light verb suru (cf. Kageyama (1982)).

One may consider here that the mimetics in mimetic compounds can also undergo a similar conversion process to verbs like turu. In fact, the following example seems to indicate that the mimetic gains VN status:
(26) Otto no kudaranai hanasi ni iraira-sita. [Verb] husband Gen silly talk at irritated-get.Past 'I got irritated by my husband's silly talk.'

In (26), the mimetic iraira is directly followed by sita, which is the past form of the light verb suru. As mentioned in Section 2.2, co-occurrence with suru is one of the characteristics of VNs. Thus, one might think that the example in (26) indicates that iraira itself can be turned into a VN through conversion. If this is the case, it is possible to consider that mimetic compounds are headed by a VN converted from a mimetic, as represented in (27); we therefore no longer need to rely on the semi-lexical VN $A C T I O N$ to account for the categorial status of the compounds and the argument-predicate or the adjunct-predicate relations discussed in Section 4.1. 
(27)

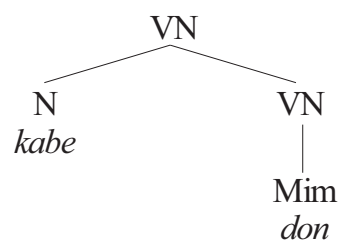

However, this line of analysis is not tenable because mimetics are unable to become VNs. Let us first consider the following contrast:
a. dondon $\left\{\right.$-to $\left./ *_{-}-\mathrm{o}\right\} \quad$ suru
Mim \{-Quot / -Acc $\}$ do
'(Someone) thumps (something).' study $\{$-Acc / -Quot $\}$ do
'(Someone) studies.'
b. benkyoo $\{-o / *$-to $\}$ suru

As noted in Section 2.2, mimetic verbs allow the quotative marker -to to appear between mimetics and suru, but not the accusative case marker $-o$ as in (28a). VNs, on the other hand, show the opposite behavior; as in (28b), they can be followed by $-o$, but not by -to, when used with suru. This contrast suggests that mimetics cannot be turned into $\mathrm{VN}$ even when they co-occur with suru.

Another piece of evidence comes from deletion in coordinate constructions. First, let us observe the following examples where the uncontroversial VNs ryokoo and tozan co-occur with si, the adverbial form of suru:
a. Natuyasumi-ni-wa, ani-wa kaigai-ni ryokoo summer vacation-in-Top older brother-Top abroad travel si, otooto-wa Huzisan-ni tozan sita. do younger brother-Top Mt. Fuji-Dat climb do.Past 'In summer vacation, an older brother traveled abroad, and a younger brother climbed Mt. Fuji.'
b. *Ani-wa kaigai-ni ryokoo, An older brother-Top abroad travel, otooto-wa Huzisan-ni tozan sita. a younger brother-Top Mt. Fuji climb do.Past 'An older brother traveled abroad and a younger brother climbed Mt. Fuji.'

(Kageyama (1993: 261))

In (29a), the VN ryokoo is directly followed by si. This verbal element cannot be deleted in this construction, as shown by the ungrammaticality of (29b). Mimetics with suru, on the other hand, show different behaviors in 
the construction. For example, the sentence in (30) contains the mimetics dondon and tonton, both of which are accompanied by forms of suru (i.e. si and sita, respectively).

(30) Taroo-wa tobira-o dondon(si), Jiroo-wa tonton sita. Taro-TOP door-Acc Mim(do), Jiro-TOP Mim do.Past 'Taro thumped at the door and Jiro rapped at an(other) door.'

(cf. Kageyama (1993: 261))

In this sentence, the verb si following dondon can be deleted. This shows that the mimetic-suru complex has a different status from the VN-suru complex. ${ }^{15}$ These examples lead us to conclude that mimetics are not VNs even though they occur in VN positions.

In addition, theoretical problems arise regarding the conversion of mimetics. Recall that mimetics "inherently do not have categorial status" (Tsujimura (2005: 144), see also Akita (2009)). This means that mimetics lack specifications for the features $[ \pm \mathrm{V}],[ \pm \mathrm{N}]$ and $[ \pm \mathrm{A}]$. As a result, they cannot undergo the process of feature switching, or conversion.

The above discussion shows, both empirically and theoretically, that mimetics cannot undergo conversion. Hence, the word-formation process given in (27) is untenable; we have to rely on another process to coin mimetic compounds. Note that the impossibility of converting mimetics does not mean that no morphological processes are applied to them. If there are processes that do not impose categorial restriction on their input elements, they can be applied to mimetics. One such process is compounding (cf. Kageyama (1982: 224)). The data in (31) show that mimetics can take part in compounding (see also Tamori and Schourup (1999)).

$$
\begin{aligned}
& \text { a. (Koneko-ga) [yotiyoti-aruki }]_{\mathrm{VN}} \text { suru sugata-ga totemo } \\
& \text { (kitten-Nom) [Mim-walk] do figure-Nom very } \\
& \text { kawairasii desu. } \\
& \text { cute Cop }
\end{aligned}
$$

'The kitten waddling along is very cute.'

(https://www.youtube.com/watch?v=u0BTsF2kQgs)

15 So far, we have demonstrated that the categorial status of mimetic compounds is $\mathrm{VN}$, which predicts that mimetic compounds behave in the same way as VNs like ryokoo and tozan; they do not tolerate the deletion of $s i$, which is attached to the first mimetic compound. This prediction is borne out:

(i) Taroo-wa kabe-don *(si), Jiroo-wa ago-kui sita. Taro-Top wall-Mim (do) Jiro-Top chin-Mim do.Past 'Taro did kabe-don, and Joro did ago-kui.' 
b. karesi-kara sarete $[k y u n-s i]_{\mathrm{VN}}$ suru itutu-no koto boy friend-by be.done Mim-die do five-Gen thing 'five actions of one's boyfriend making one's heart skip a beat' (http://future-next.com/karesikarakyunsi_koto5/)

In (31a), for example, the mimetic yotiyoti is combined with the converted noun aruki, forming the compound yotiyoti-aruki. Notice that the compound is a VN since it is headed by the VN aruki. In fact, yotiyoti-aruki is followed by the light verb suru. Similarly, in (31b), the mimetic kyun combines with $s i$, resulting in a VN compound.

It is reasonable to assume that the same morphological processes as (31) are involved in mimetic compounds. The mimetics in mimetic compounds are combined with the semi-lexical VN $A C T I O N$, yielding the VN compound [mimetic- $A C T I O N]_{\mathrm{VN}}$, which is then combined with a noun. $A C T I O N$ provides us with a morphologically permissible process to form mimetic compounds without creating empirical or theoretical problems.

4.3. Mimetic Compounds Cannot Be Nouns: Evidence from Recoverability

We have argued that mimetic compounds are compounds headed by the semi-lexical VN ACTION. As evidence for this, we have shown that mimetic compounds are subject to the same restrictions as ordinary deverbal compounds, or compounds headed by converted VNs (see Section 4.1). However, there is a case where mimetic compounds behave differently from regular deverbal compounds. In this subsection, after surveying the difference between mimetic compounds and ordinary deverbal compounds, we will demonstrate that this difference arises from the very nature of silent semi-lexical elements.

First, let us focus on deverbal compounds. Deverbal compounds contain VNs converted from verbs as heads, which gives the compounds the categorial status VN. These compounds are thus compatible with the light verb suru, as shown in (25), which is repeated as (32).$$
\left[[\text { sakana }]_{\mathrm{N}}-[\text { turi }]_{\mathrm{VN}}\right]_{\mathrm{VN}}(\text { suru }) \text { fish-fish (do) 'angling, fishing' }
$$

Note that not all deverbal compounds are VNs. There are deverbal compounds that designate "concrete objects such as instruments, agents, and places" (Kageyama (1982: 225)). In such cases, the meaning is not overtly marked; that is, deverbal compounds designating concrete objects seemingly have the same morphological composition as those designating activities. For example, the compound kane-moti in (33) contains as its head the converted VN moti, the adverbial form of the verb motu 'have,' which 
in turn is combined with the noun kane 'money.' Although this morphological composition is not different from those of deverbal compounds like sakana-turi in (32), it does not express an activity but a person with a particular feature, namely 'a rich person.' In fact, it is not compatible with suru (*kane-moti suru lit. 'do a rich person' (Kageyama (1982: 225), with a slight modification)). Kageyama (1982) assumes that such deverbal compounds are turned from VNs into pure nouns through lexical reanalysis, as seen in (33).

(33) $\left[[\text { kane }]_{\mathrm{N}}-[\text { moti }]_{\mathrm{VN}}\right]_{\mathrm{VN}} \rightarrow[\text { kane-moti }]_{\mathrm{N}}$ money-have 'a rich person' (cf. Kageyama (1982: 225)) Deverbal compounds designating concrete objects can be found easily (cf. Ito and Sugioka (2002)), which indicates that this lexical reanalysis is a productive process applied to VN compounds.

As we have shown that mimetic compounds are VNs, it is predicted that they can be turned into pure nouns designating concrete objects through reanalysis. However, it is not the case. The only possible interpretation of mimetic compounds seems to be that of events. Thus, they are always compatible with suru:
a. kabe-don (suru)
wall-Mim (do)
$(=(11 \mathrm{a}))$
b. ago-kui (suru)
chin-Mim (do)
$(=(11 b))$
c. mune-kyun (suru)
heart-Mim (do)
$(=(11 \mathrm{c}))$
d. kao-piku (suru)
face-Mim (do)
(=(11d))
e. zintensya-burabura (suru)
bicycle-Mim (do)
$(=(11 \mathrm{e}))$
f. neko-banban (suru)
cat-Mim (do)
(=(11f))
g. yubi-pattin (suru)
finger-Mim
h. atama-don (suru)
head-Mim
(cf. (17b))

Since mimetic compounds always function as VNs, they require overt nominal elements in order to express concrete objects. For example, kabe-don can express a person only when it is combined with a noun such as otoko 'man,' as exemplified in (35).

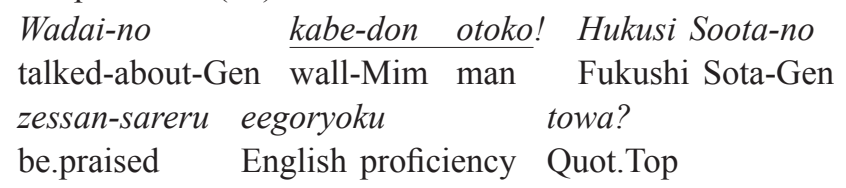

'The talked-about kabe-don man! What are Sota Fukushi's excellent English skills like?'

(http://www.weddingpark.net/magazine/2716/, underlining ours) The compound kabe-don otoko in (35) means a man who does kabe-don. When otoko is omitted from this compound, it cannot be interpreted in such 
a way; when there is a need to denote a concrete object related to the action or event expressed by a mimetic compound, it is obligatorily combined with a relevant overt noun such as otoko. The same holds true for other mimetic compounds. This indicates that mimetic compounds resist being reanalyzed as pure nouns. In this respect, mimetic compounds differ from ordinary deverbal compounds.

Why is it, then, that unlike ordinary deverbal compounds, mimetic compounds are not turned into pure nouns through reanalysis? We will examine this question by considering functional aspects, especially, the notion of "recoverability."

Kayne (2005) argues that silent nouns must occur in the environment where their presence and semantic contents can be recovered. For example, let us consider the case of the silent NUMBER.

(36) a few NUMBER books According to Kayne (2005: 243), NUMBER in (36) is licensed by the feature [+number], which is arguably included in the lexical make-up of the number adjective few.

Similarly, silent $A C T I O N$ in the head position of mimetic compounds should be recoverable. We have assumed that $A C T I O N$ bears the $\mathrm{VN}$ property. If the category of mimetic compounds is $\mathrm{VN}$, the existence of $A C T I O N$ is readily recoverable: This silent $\mathrm{VN}$ determines the categorial status of compounds as heads and we can thus conversely go back to that categorial determinant based on the entire categorial status of the compounds. However, if the category of mimetic compounds is turned into pure nouns by reanalysis, the silent $A C T I O N$ fails to be recovered by recourse to the categorial status of the compounds. Therefore, mimetic compounds cannot be pure nouns. It is the very silent nature of $A C T I O N$ that keeps mimetic compounds from changing into pure nouns. Accordingly, the difference between mimetic compounds and ordinary deverbal compounds supports our analysis with the silent semi-lexical VN ACTION.

5. The Structural Status of Mimetic Compounds: Are They Postsyntactic Compounds?

This section addresses the question concerning the structural status of mimetic compounds: Are they formed lexically, as assumed so far? In Section 3, we proposed that mimetic compounds are formed through the compounding process in which the silent semi-lexical VN ACTION is involved. However, one might postulate another possibility of their structure: 
They could have semantically corresponding sentences as their underlying forms, a possibility that mimetic compounds are not lexical, but rather syntactic compounds. Let us take kabe-don as an example. As pointed out in Section 3, kabe-don roughly corresponds, in an intuitive sense, to a sentential form such as (37).

$$
\begin{aligned}
& \text { Kabe-o don-to suru. } \\
& \text { wall-Acc Mim-Quot do } \\
& \text { 'One bangs the wall.' }
\end{aligned}
$$

This structure would then serve as input to the form kabe-don, which is derived by truncating the accusative marker $-o$, the quotative marker -to, and the light verb suru. This derivational process yields a result similar to what Shibatani and Kageyama (1988) call postsyntactic compounds. For example:

$$
\begin{array}{llllllll}
\text { [[ Kanai } & \text { ga } & \text { Amerika } & \text { o } & \text { hoomon ] } & \text { no } & \text { ori }] & n i \\
\text { my.wife } & \text { Nom } & \text { America } & \text { Acc } & \text { visit } & \text { Gen } & \text { occasion } & \text { on }
\end{array}
$$
wa, iroiro osewa ni narimasita.

Top much hospitality Adv.Part she.received

'Thank you for your generous hospitality when my wife visited America.'

(Shibatani and Kageyama (1988: 455))

The embedded sentence kanai ga Amerika o hoomon, according to Shibatani and Kageyama, can be shortened to result in the following bracketed compound: ${ }^{16}$

$\begin{array}{lllll}\text { (39) kanai } & \text { ga } & \text { [Amerika:hoomon] } & \text { no } & \text { ori } \\ \text { my.wife } & \text { Nom } & \text { America:visit } & \text { Gen } & \text { occasion }\end{array}$

(Shibatani and Kageyama (1988: 457))

The compound Amerika:hoomon is postsyntactic in that it is based on a syntactic, not lexical, input in (38) (' $:$ ' in (39) indicates that the compound in question is a postsyntactic compound, and is distinguished from '-', which is used here to mark the relevant sequence as a lexical compound).

If mimetic compounds belonged to the class of postsyntactic compounds

16 Postsyntactic compounds like (39) are severely restricted to embedded positions headed by a noun denoting a certain time relation (Shibatani and Kageyama (1988)), such as [...] no ori in (38); syntactic phrases appearing in this environment can become an input to compounds derived at the postsyntactic level. In other words, if Amerika and hoomon, for example, are combined in a non-embedded environment, the resulting compound is a lexical compound and is completely different from a postsyntactic one; Amerika-hoomon is pronounced without pause between the two constituents and no longer preserves the pitch pattern of each constituent. 
(e.g. kabe:don), the semi-lexical VN $A C T I O N$ would not be required to ensure the semantic relation between the mimetic and the left-hand element, each of which would belong to a different semantic dimension (see Section 2.1). This is because such a relationship would already be guaranteed by the light verb suru in the underling sentential form; in that case, our proposal revolving around the lexical level would be dismissed. This possibility, however, is not tenable; genuine postsyntactic compounds and mimetic compounds differ in several aspects. In particular, postsyntactic compounds have phrasal characteristics that are rooted in the underlying sentential inputs, whereas such characteristics are not observable in mimetic compounds. In what follows, we will discuss the discrepancies between these two types of compounds, excluding the possibility where mimetic compounds have structural bases in sentential forms, and concluding that they are formed at the lexical level.

Let us begin with the phonological aspects. Mimetic compounds, as already discussed in Section 2.1, show compounding phonological patterns. Postsyntactic compounds, on the other hand, are pronounced "with the inherent pitch patterns of the individual members kept intact and a slight pause put after the first member" (Shibatani and Kageyama (1988: 459)); phonologically, they have phrasal status. Thus, the postsyntactic compound Amerika:hoomon in (40b) involves a slight pause immediately after Amerika and preserves the underlining pitch pattern of each constituent shown in (40a) (Amerika-hoomon shows a compound phonological pattern).
a. Amerika o hoomon no sai (overline = high pitch) America Acc visit Gen occasion 'on the occasion of visiting America'
b. [Amerika:hoomon] no sai [postsyntactic compound] [America:visit]

cf. Amerika-hoomon

America visit
(Shibatani and Kageyama (1988: 460)) [lexical compound] (Shibatani and Kageyama (1988: 459))

A discrepancy between these two types of compounds can also be observed semantically. The semantic relation between the constituents of postsyntactic compounds is contingent on their underlying sentential forms, which strictly restricts their possible interpretations. Shibatani and Kageyama (1988: 470) give the following contrasts between postsyntactic and lexical compounds, showing the difference in various possible interpretations: 
(41) Instrumental:

a. enpitu-gaki 'writing with a pencil,' mizu-arai 'washing with cold water,' basu-tuugaku 'going to school by bus'

b. *densanki:keisan-tyuu / no sai computer:calculate

cf. densanki de keisan-tyuu $n i$ 'when calculating with a computer'

Source:

a. gaikoku-gaeri 'the state of having returned from abroad,' huro-agari 'the state of having taken a bath' (lit. 'getting out of a bathtub')

b. *Amerika:kikoku-go / no sai

America:homecoming

cf. Amerika kara kikoku-go / no sai 'when coming back from America'

'Outer' Location:

a. iso-zuri 'fishing near the shore,' madoguti-watasi 'handing (goods) at the window,' Amerika-umare 'being born in America'

b. *resutoran:syokuzi-tyuu / no sai restaurant:dining cf. resutoran de syokuzi-tyuu ni 'when dining at a restaurant' Manner:

a. hitori-aruki 'walking alone,' naname-yomi 'skimming through a book,' sinkon-ryokoo 'honeymoon'

b. *abekku:sanpo-tyuu / no sai

together:walk

cf. abekku de sanpo-tyuu $n i$ 'when taking a walk with one's girl/boy-friend'

As shown in the a-examples, lexical compounds allow a range of semantic relations between the constituents, none of which are available in postsyntactic compounds, as seen in the b-examples. Shibatani and Kageyama conclude that the internal relations of lexical compounds are determined pragmatically, whereas those of postsyntactic compounds "are strictly compositional in precisely the same way as sentences are" (Shibatani and Kageyama (1988: 478)).

Mimetic compounds are similar to lexical compounds, rather than postsyntactic compounds; we can easily find examples where internal relations appear to be determined pragmatically. For example: 
a. atama-don [instrumental] $(=(17 b))$ head-Mim

'the act of a man cornering a woman with his head'

b. koosaten-zukyun [location] intersection-Mim

'an emotional movement that occurs when a person faces another person while waiting for a traffic light at an intersection and they immediately fall in love'

(http://www.honda.co.jp/GIORNO/special/giorkyun/)

c. neko-banban [beneficiary]

Atama in (42a) and koosaten in (42b) respectively have an instrumental relation to don and a locative relation to zukyun; both of these relations seem to be impossible in the case of postsyntactic compounds. Neko in (42c), as discussed, establishes a more peculiar relation to banban: Neko is a beneficiary of the act of banging the car hood. These facts suggest that mimetic compounds are not coined based on sentential forms.

Mimetic compounds behave differently from postsyntactic compounds with respect to the referentiality of the left-hand element. As illustrated in (43), the left-hand constituent zikken of the postsyntactic compound zikken:syuuryoo is allowed to be modified by the demonstrative modifier kono, showing that it has a referential property (Shibatani and Kageyama (1988)).

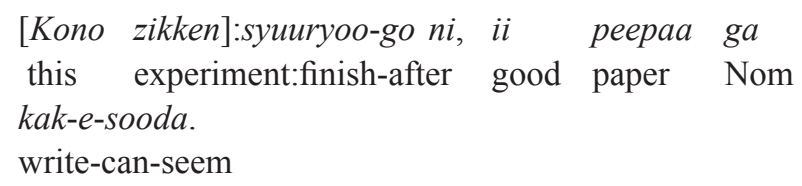

'After this experiment is completed, it appears that I can write a good paper.'

(Shibatani and Kageyama (1988: 471))

Shibatani and Kageyama (1988) attribute this property to the sentential origin of postsyntactic compounds, in the sense that their constituents inherit the referentiality of the noun phrases in the syntactic structures. On the other hand, mimetic compounds do not allow modification of the left-hand element by a demonstrative modifier, as illustrated in (44).

$$
\begin{gathered}
\text { (44) *soko no kabe-don } \\
\text { that Gen wall-Mim }
\end{gathered}
$$

In sum, mimetic compounds behave differently from postsyntactic compounds. Specifically, unlike postsyntactic compounds, they have no characteristics indicating that they have sentential inputs. It is therefore reasonable to say that mimetic compounds should be regarded as compounds 
coined at the lexical level, as assumed thus far.

\section{Theoretical Implications}

As mentioned in Section 1, semi-lexical categories have remained less than fully understood. This study thus aimed to deepen our understanding of semi-lexical categories by exploring Japanese mimetic compounds. We proposed that mimetic compounds include the semi-lexical VN ACTION. To our knowledge, no items corresponding to $A C T I O N$ have been discussed in the literature. Hence, this newly identified item will play a role in clarifying the nature of semi-lexical categories. The critical properties of $A C T I O N$ in this context are the following: (i) $A C T I O N$ has the category VN and (ii) it is a silent element that has no corresponding lexical item. The subsequent subsections show what these properties imply concerning semilexical categories.

\subsection{The Types of Semi-Lexical Categories and Japanese}

The items classified as semi-lexical categories in previous studies have been limited to nouns, verbs, adjectives and prepositions (cf. Emonds (1985, 2000), Corver and van Riemsdijk (2001b)), and less attention has been paid to other classes. This is inevitable, in a sense, because most previous studies focus mainly on English and other European languages, which lack VNs (cf. Shibatani (1990)). Consequently, it has not been clear whether there are semi-lexical elements that belong to classes other than the four major ones. However, by analyzing Japanese mimetic compounds, we have demonstrated the existence of the semi-lexical VN ACTION. This shows that the set of semi-lexical categories contains not only the four major categories, but also other categories like VN.

Japanese has another category that European languages do not have: adjectival nouns (AN). They behave as adjectives in some respects and as nouns in others. Here, the question arises as to whether ANs can be semilexical elements. Our conjecture is that there should be cases in which semi-lexical ANs are involved. One possible candidate is the following compound: ${ }^{17}$

(45) kin-pika gold-Mim 'gaudy'

Kin-pika in (45) is similar to the mimetic compounds we have dealt with

17 Example (45) was pointed out to us by Yoko Sugioka (personal communication). 
in this paper as the mimetic appears in the right-hand position. However, it behaves differently from them. While mimetic compounds can co-occur with the light verb suru, kin-pika cannot:

\section{(46) *kin-pika suru}

Rather, the following facts suggest that kin-pika is an AN. According to Kageyama (1982: 217), ANs can be nominalized by the suffix -sa '-ness' (e.g. odayaka-sa 'gentleness'), and they take the inflectional ending -na in prenominal position (e.g. odayaka-na hito 'a gentle person'). Kin-pika behaves in the same way as ANs:

$$
\begin{array}{ll}
\text { a. } & \text { kin-pika-sa } \\
& \text { gold-Mim-ness } \\
\text { 'gaudiness' }
\end{array}
$$

\author{
b. kin-pika-na (ie) \\ gold-Mim-Infl (house) \\ '(the house) which is gaudy'
}

So, the compound in (45) has a categorial status as AN. It may be possible to assume that the head position is occupied by a silent semi-lexical $\mathrm{AN}$, which provides the compound with the AN status: ${ }^{18}$

(48) [[kin-pika $]$ AN]

If the assumption here is correct, ANs also exist in semi-lexical categories. This issue, however, is beyond the scope of our discussion. We leave it for future research.

6.2. The Independence of Semi-Lexical Categories from Lexical Categories

The existence of $A C T I O N$ has another implication for studying semilexical categories. As proposed, ACTION is a silent semi-lexical element. What is crucial here is that it does not have an overt (lexical) counterpart. This property has an implication for the independence of semi-lexical categories from lexical categories.

Before proceeding to discuss the implication, let us consider the relationship between semi-lexical categories and lexical categories. Many semilexical items identified in previous studies seem to presuppose the existence of lexical counterparts. For example, as exemplified in Section 1, the

18 Unlike the mimetics in the discussed mimetic compounds, the mimetic pika does not establish the argument-predicate or the adjunct-predicate relation with the left-hand element kin. This is because they are assumed to be an appositional compound that "refers to one entity that is characterized by both members of the compound" (Plag (2003: 146)): Kin-pika characterizes the entity referred to as gold and shining. This type of compound "could be said to have two semantic heads, neither of them being subordinate to the other" (Plag (2003: 146)). Thus, we temporarily assume that pika first combines with kin, establishing an equal relation. Then [kin-pika] combines with the silent semi-lexical AN. 
adjectives real, pretty, awful and damned can function as both lexical and semi-lexical elements. Some may argue that these words do not belong to the class of semi-lexical elements, but are merely one usage of regular lexical adjectives with bleached meanings.

This argument raises the question of whether a semi-lexical category should be established as an independent class from the class of lexical elements in the first place. The existence of $A C T I O N$ provides an answer to this question: We need to assume the semi-lexical category as an independent category. This answer comes from the property of $A C T I O N$ that it is always silent and does not have a lexical (overt) counterpart. This means that $A C T I O N$ does not depend on lexical categories; it cannot be considered to be one usage of a lexical item but rather stands on its own in semi-lexical categories. If semi-lexical elements originate in lexical elements, we cannot appropriately deal with $A C T I O N$. ACTION can be given a secure place in grammar only by assuming a class of semi-lexical elements, which is independent from lexical categories. ${ }^{19}$

The above considerations also provide an answer to a question posed by Harves and Myler (2014), who assume a silent adjectival predicate. They assume such a silent item in the context of constructions like (49).

(49) John is yet to visit Paris.

(Harves and Myler (2014: 233), with modifications) In (49), the negative polarity item yet occurs, and so it must be licensed by an appropriate element. However, the sentence does not contain a visible licenser. Harves and Myler (2014) argue that yet in (49) is actually licensed by a silent adjectival predicate, as represented in (50).

(50) $\mathrm{John}_{i}$ is yet ${ }_{j}$ ???-ED/-EN $\left[{ }_{\text {TP }}<\mathrm{John}>_{i}\right.$ to visit Paris $<$ yet $>_{j}$ ].

(cf. Harver and Myler (2014: 237))

19 In context, we refer to differences between semi-lexical and lexical categories. One might wonder how semi-lexical categories differ from functional categories. Previous studies have, explicitly or implicitly, focused on the differences between semi-lexical and lexical categories. However, they have not paid enough attention to the differences between semi-lexical and functional categories. Based on the definition of semi-lexical items in Section 1, they are different from ordinary functional items in that they can belong to any of the four syntactic categories, verb, noun, adjective and preposition. In other words, unlike functional categories, they can be defined by the composition of binary features like lexical categories.

In fact, $A C T I O N$ differs from regular functional elements in that it is a $\mathrm{VN}$ and thus it can be defined by the three binary features $[ \pm \mathrm{V}],[ \pm \mathrm{N}]$ and $[ \pm \mathrm{A}]$, which define the major Japanese lexical categories as shown in Section 4.2. 
Although Harves and Myler (2014) convincingly prove the existence of such a silent element, they themselves point out a problem. That is, they have no choice but to represent the silent element by the notation ???-ED/-EN because they "have not yet been able to find an overt counterpart of such a predicate in English" (Harves and Myler (2014: 237)). After examining one possible candidate, they leave it for future research to identify an overt counterpart of the silent adjectival predicate in (50). However, if we assume the analysis concerning the semi-lexical VN ACTION developed above, it is not necessarily the case that an overt counterpart exists. ${ }^{20}$ Rather, the lack of such an overt counterpart shows the necessity of assuming semi-lexical categories as categories in their own right. Thus, we can conclude that together with $A C T I O N$, observed in mimetic compounds, ???-ED/-EN supports the independence of semi-lexical categories.

\section{Concluding Remarks}

It has been recognized that there are elements that show properties of both lexical and functional categories, and these elements have been investigated under the label of semi-lexical categories. Compared to lexical and functional categories, semi-lexical categories are less well understood. This is partially due to the fact that semi-lexical elements in non-European languages such as Japanese and in word-formation have been inadequately explored. In light of this, we have examined Japanese mimetic compounds. Mimetic compounds show apparently peculiar behavior, as they do not seem to follow the RHR and their categorial status is restricted to $\mathrm{VN}$. We have tried to account for this peculiarity by assuming that the silent semi-lexical VN $A C T I O N$ is in the head position (e.g. [kabe [don $A C T I O N]]$ ). We have then demonstrated the validity of our proposal by showing that it compares favorably against alternative analyses.

Our proposal enables us to deepen our knowledge of semi-lexical categories in two areas. Firstly, VNs can fall under semi-lexical categories. Sec-

${ }^{20}$ Harves and Myler (2014) do not refer to the silent adjectival predicate as a semi-lexical element. However, their analysis is in line with studies including Kayne (2005). Thus, given Corver's (2008) characterization of semi-lexical categories, it is safe to consider this predicate as a semi-lexical item. In addition, ???-ED/-EN is devoid of semantic content and behaves like a functional category as it serves as a grammatical licenser of the negative polarity item yet. ???-ED/-EN thus reflects characteristics of semi-lexical categories. 
ondly, "semi-lexical" needs to be established as an independent category.

Finally, we now turn to areas of future research. An immediate question is whether $A C T I O N$ is used elsewhere other than mimetic compounds. Finding other examples where $A C T I O N$ occurs will further confirm its existence. We can also ask the question of whether there are semi-lexical VNs in Japanese other than ACTION. Beyond these questions, we need more cross-linguistic examination. Some other languages like Korean have VNs, so we predict that these languages also bear semi-lexical VNs. Answering these remaining questions will also shed new light on the study of semi-lexical categories. We hope that this paper contributes to exploring the frontiers of research in semi-lexical categories.

\section{REFERENCES}

Akita, Kimi (2009) A Grammar of Sound-Symbolic Words in Japanese: Theoretical Approaches to Iconic and Lexical Properties of Mimetics, Doctoral dissertation, Kobe University.

Corver, Norbert (2008) "On Silent Semi-lexical Person," Lingue e Linguaggio 7, $5-24$.

Corver, Norbert and Henk van Riemsdik (2001a) "Semi-lexical Categories," Semilexical Categories: The Function of Content Words and the Content of Function Words, ed. by Norbert Corver and Henk van Riemsdijk, 1-19, Mouten de Gruyter, Berlin.

Corver, Norbert and Henk van Riemsdijk (ed.) (2001b) Semi-lexical Categories: The Function of Content Words and the Content of Function Words, Mouten de Gruyter, Berlin.

Emonds, Joseph E. (1985) A Unified Theory of Syntactic Categories, Foris, Dordrecht.

Emonds, Joseph E. (2000) Lexicon and Grammar: The English Syntacticon, Mouton de Gruyter, Berlin.

Emonds, Joseph E. (2001) "The Flat Structure Economy of Semi-lexical Heads," Semi-lexical Categories: The Function of Content Words and the Content of Function Words, ed. by Norbert Corver and Henk van Riemsdijk, 23-66, Mouten de Gruyter, Berlin.

Hamano, Shoko (1998) The Sound-Symbolic System of Japanese, Kurosio, Tokyo.

Harves, Stephanie and Neil Myler (2014) "Licensing NPIs and Licensing Silence: Have/Be yet to in English," Lingua 148, 213-239.

Ito, Takane and Yoko Sugioka (2002) Go no Sikumi to Gokeesee (Structure of Words and Word-Formation), Kenkyusha, Tokyo.

Kageyama, Taro (1982) "Word Formation in Japanese," Lingua 57, 215-258.

Kageyama, Taro (1993) Bunpoo to Gokeesee (Grammar and Word-Formation), 
Hituzi, Tokyo.

Kageyama, Taro (1996) Doosi Imiron: Gengo to Ninti no Setten (Verb Semantics: The Language-Cognition Interface), Kurosio, Tokyo.

Kageyama, Taro (2007) "Explorations in the Conceptual Semantics of Mimetic

Verbs," Current Issues in the History and Structure of Japanese, ed. by Bjarke

Frellesvig, Masayoshi Shibatani and John C. Smith, 25-82, Kurosio, Tokyo.

Kageyama, Taro and Michiaki Saito (2016) "Vocabulary Strata and Word Formation

Processes," Handbook of Japanese Lexicon and Word Formation, ed. by Taro

Kageyama and Hideki Kishimoto, 11-50, Mouton de Gruyter, Boston/Berlin.

Kayne, Richard S. (2005) Movement and Silence, Oxford University Press, New York.

Kayne, Richard S. (2007) "Several, Few and Many," Lingua 117, 832-858.

Kita, Sotaro (1997) "Two-Dimensional Semantic Analysis of Japanese Mimetics," Linguistics 35, 379-415.

Kubozono, Haruo (1988) "Constraints on Phonological Compound Formation," English Linguistics 5, 150-169.

Kubozono, Haruo (1995) Gokeesee to On'inkoozoo (Word-Formation and Phonological Structure), Kurosio, Tokyo.

Nasu, Akio (2002) Nihongo Onomatope no Gokeesee to Inritukoozoo (Word-Formation and Prosodic Structures of Japanese Mimetics), Doctoral dissertation, University of Tsukuba.

Plag, Ingo (2003) Word-Formation in English, Cambridge University Press, Cambridge.

Shibatani, Masayoshi (1978) Nihongo no Bunseki (An Analysis of Japanese), Taishukan, Tokyo.

Shibatani, Masayoshi (1990) The Languages of Japan, Cambridge University Press, Cambridge.

Shibatani, Masayoshi and Taro Kageyama (1988) "Word Formation in a Modular Theory of Grammar: Postsyntactic Compounds in Japanese," Language 64, 451-484.

Shimada, Masaharu (2013) "Coordinated Compounds: Comparison between English and Japanese," SKASE Journal of Theoretical Linguistics 10, 77-96.

Sugioka, Yoko (1989) "Haseigo niokeru Doosisosee no Uketugi (Inheritance of Verb Features in Derived Nouns)," Nihongogaku no Sintenkai (New Developments of Japanese Linguistics), ed. by Susumu Kuno and Masayoshi Shibatani, 167-185, Kurosio, Tokyo.

Tamori, Ikuhiro and Lawrence Schourup (1999) Onomatope: Keetai to Imi (Onomatopoeia: Form and Meaning), Kurosio, Tokyo.

Tsujimura, Natsuko (2005) "A Constructional Approach to Mimetic Verbs," Grammatical Constructions: Back to the Roots, ed. by Mirjam Fried and Hans C. Boas, 137-154, John Benjamins, Amsterdam/Philadelphia.

Tsujimura, Natsuko (2014) An Introduction to Japanese Linguistics, 3rd ed., Blackwell, Cambridge, MA.

Williams, Edwin (1981) “On the Notions 'Lexically Related' and 'Head of a Word'," 
Linguistic Inquiry 12, 245-274.

[received April 1, 2016, revised and accepted September 10, 2016]

(Ryohei Naya)

1-1-1 Tennoudai

Tsukuba-shi

Ibaraki 305-8571

e-mail: naya.ryohei@gmail.com

(Keita Ikarashi)

1-1 Kadota, Yahata, Ikki-machi

Aizuwakamatsu-shi

Fukushima 965-8570

e-mail: ikarashi@jc.u-aizu.ac.jp 